\title{
Influence of annual atmospheric tide asymmetry on annual anomalies of the ionospheric mean state
}

\author{
ZhiPeng Ren ${ }^{1,2,3,4 *}$, WeiXing Wan ${ }^{1,2,3,4}$, JianGang Xiong ${ }^{1,2,3,4}$, and Xing $\mathrm{Li}^{5,6}$ \\ ${ }^{1}$ Key Laboratory of Earth and Planetary Physics, Institute of Geology and Geophysics, Chinese Academy of Sciences, Beijing 100029, China; \\ ${ }^{2}$ Innovation Academy for Earth Science, Chinese Academy of Sciences, Beijing 100029, China; \\ ${ }^{3}$ Beijing National Observatory of Space Environment, Institute of Geology and Geophysics, Chinese Academy of Sciences, Beijing 100029, China; \\ ${ }^{4}$ College of Earth and Planetary Sciences, University of the Chinese Academy of Sciences, Beijing 100049, China; \\ ${ }^{5}$ School of Space and Environment, Beihang University, Beijing 100083, China; \\ ${ }^{6}$ Key Laboratory of Space Environment Monitoring and Information Processing, Ministry of Industry and Information Technology, Beijing 100083, China
}

\section{Key Points:}

- The annual asymmetry of the migrating diurnal and semi-diurnal tides can affect the ionospheric annual anomaly

- The tidal influence varies with altitude, latitude, and solar flux level

- The tide can affect the EIA structure in the ionospheric annual anomaly

Citation: Ren, Z. P., Wan, W. X., Xiong, J. G., and Li, X. (2020). Influence of annual atmospheric tide asymmetry on annual anomalies of the ionospheric mean state. Earth Planet. Phys., 4(5), 429-435. http://doi.org/10.26464/epp2020041

\begin{abstract}
Through respectively adding June tide and December tide at the low boundary of the GCITEM-IGGCAS model (Global Coupled Ionosphere-Thermosphere-Electrodynamics Model, Institute of Geology and Geophysics, Chinese Academy of Sciences), we simulate the influence of atmospheric tide on the annual anomalies of the zonal mean state of the ionospheric electron density, and report that the tidal influence varies with latitude, altitude, and solar activity level. Compared with the density driven by the December tide, the June tide mainly increases lower ionospheric electron densities (below roughly the height of $200 \mathrm{~km}$ ), and decreases electron densities in the higher ionosphere (above the height of $200 \mathrm{~km}$ ). In the low-latitude ionosphere, tides affect the equatorial ionization anomaly structure $(E I A)$ in the relative difference of electron density, which suggests that tides affect the equatorial vertical $E \times B$ plasma drifts. Although the tide-driven annual anomalies do not vary significantly with the solar flux level in the lower ionosphere, in the higher ionosphere the annual anomalies generally decrease with solar activity.
\end{abstract}

Keywords: ionospheric annual anomalies; atmospheric tide; ionosphere-atmosphere coupling

\section{Introduction}

In ionospheric studies, the term "anomaly" usually refers to an inconsistency between the electron density distribution observed in the $F_{2}$ layer and the result of the Chapman theory of photoionization. The ionospheric seasonal variabilities, which are important "ionospheric anomalies", is an unresolved important question in ionospheric research. Some previous studies have focused on the differences between summer and winter and between solstice and equinox (e.g., Zhao B et al., 2007); other research has focused on the asymmetry of the ionospheric seasonal variabilities. An interesting asymmetry in the ionospheric seasonal variation is the ionospheric annual anomaly (or ionospheric annual asymmetry). The ionospheric annual anomaly is characterized by the fact that the globally-averaged electron density is more than $20 \%$ larger in the December solstice than in the June solstice (e.g., Rishbeth and

Correspondence to: Z. P. Ren, zpren@mail.iggcas.ac.cn

Received 09 MAR 2020; Accepted 27 APR 2020.

Accepted article online 05 JUN 2020.

(C) 2020 by Earth and Planetary Physics.
Müller-Wodarg, 2006). This difference has been observed in a series of ionospheric parameters, such as total electron content (TEC), F-layer peak electron density $\left(N_{\mathrm{m}} \mathrm{F}_{2}\right)$, topside ionospheric electron density, and ionospheric electron density profiles (e.g. Su YZ et al., 1998; Mendillo et al., 2005; Rishbeth and Müller-Wodarg, 2006; Liu LB et al., 2007; Zeng Z et al., 2008; Sai Gowtam and Tulasi Ram, 2017).

The ionospheric annual anomaly's physical mechanism has been listed as one of the top scientific objectives in ionosphere-thermosphere studies (Rishbeth, 2007). Using the CTIP (Coupled Thermosphere-lonosphere-Plasmasphere) model, Rishbeth and Müller-Wodarg (2006) simulated the anomaly in the ionospheric peak electron density $\left(N_{\mathrm{m}} \mathrm{F}_{2}\right)$, and found that the asymmetry of the Sun-Earth distance between the June and December solstices can partly explain the observed ionospheric annual anomaly. However, their simulated electron density anomaly was much smaller than the observed difference. Liu LB et al. (2007) studied the annual anomaly in the topside ionospheric total ion density at the height of $840 \mathrm{~km}$, and pointed out that the observed anomaly 
can be partially explained by the annual asymmetry of the atomic oxygen density at that topside ionospheric height. Using the Thermosphere-lonosphere Electrodynamics Global Circulation Model (TIEGCM), Zeng Z et al. (2008) simulated the ionospheric annual anomaly in $N_{\mathrm{m}} \mathrm{F}_{2}$, and successfully reproduced the observed $N_{\mathrm{m}} \mathrm{F}_{2}$ asymmetry. Their simulation suggested that the geomagnetic field configuration and the asymmetry of the Sun-Earth distance between the the June and December solstices are two primary processes that cause the ionospheric annual anomaly. However, why the $7 \%$ variance in the Sun-Earth distance should cause an asymmetry in ionospheric electron densities of more than $20 \%$ is still unknown. Mikhailov and Perrone $(2011,2015)$ suggested that a $7 \%$ increase in the $\mathrm{O}_{2}$ dissociation rate associated with the Juneto-December difference in the Sun-Earth distance is sufficient to explain the observed $21 \%$ annual anomaly in $N_{\mathrm{m}} \mathrm{F}_{2}$. However, using the Global Mean Model (Roble et al., 1987; Roble, 1995), Lei JH et al. (2016) simulated the annual $\mathrm{O}_{2}$ dissociation asymmetry and found that the difference in solar EUV flux cannot explain the annual asymmetry in $\mathrm{N}_{\mathrm{m}} \mathrm{F}_{2}$, and suggested, therefore, that the $\mathrm{O}_{2}$ dissociation and atomic oxygen production mechanism are not the major drivers of the ionospheric annual anomaly. Using the TIEGCM, Dang T et al. (2017) simulated the influence on the annual ionospheric $N_{\mathrm{m}} \mathrm{F}_{2}$ anomaly of the June-to-December change in the Sun-Earth distance, and found that the distance change affects photochemical processes, thermospheric composition, and ionospheric diffusion.

Atmospheric tide can affect the coupled ionosphere-thermosphere system. Forbes et al. (1993) utilized the NCAR TIGCM to simulate tidal influences on the ionosphere and the thermosphere, and found that the upward propagating migrating tide can accelerate, heat, and mix the composition of the coupled ionosphere-thermosphere system. Jones et al. (2014) simulated impacts of vertically propagating tides on the mean state of the ionosphere and thermosphere, and found that the non-migrating tide DE3 also can affect the ionospheric mean state. Ren ZP et al. (2014) simulated the ionospheric influence of the DE3 tide, and found that it affects the equinoctial asymmetry of the zonal mean ionospheric electron density. Because the intra-annual variation of the atmospheric tide shows obvious annual asymmetry, the atmospheric tide may also affect the annual anomaly of the ionospheric mean states. The migrating diurnal and semi-diurnal tides both show obvious annual asymmetry, and may affect the ionospheric annual anomaly (see Forbes et al. (1993, 2008), Mukhtarov and Pancheva (2009) and Jones et al. (2014)). However, because the propagation and interactions between different tides are nonlinear, tidal influences on the ionospheric annual anomaly are very complex. Hence, in this paper, we will investigate mainly the atmospheric tide, using the GCITEM-IGGCAS and TIME3D-IGGCAS models to simulate its influence on the annual anomaly of the ionospheric zonal mean states.

\section{Model Descriptions and Inputs}

To simulate the highly coupled and complex chemical and physical processes in the coupled ionosphere-thermosphere system, the Global Coupled Ionosphere-Thermosphere-Electrodynamics Model, Institute of Geology and Geophysics, Chinese Academy of
Sciences (GCITEM-IGGCAS) has been developed. The GCITEMIGGCAS is a three-dimensional (3-D) code with $5^{\circ}$ latitude by $7.5^{\circ}$ longitude cells in a spherical geographical coordinate system, based on an altitude grid. This model self-consistently calculates time-dependent 3-D structures of the main thermospheric and ionospheric parameters in the height range from 90 to $600 \mathrm{~km}$, including neutral number density of major species $\mathrm{O}_{2}, \mathrm{~N}_{2}$, and $\mathrm{O}$ and minor species $\mathrm{N}\left({ }^{2} \mathrm{D}\right), \mathrm{N}\left({ }^{4} \mathrm{~S}\right), \mathrm{NO}, \mathrm{He}$ and $\mathrm{H}$; ion number densities of $\mathrm{O}^{+}, \mathrm{O}_{2}{ }^{+}, \mathrm{N}_{2}{ }^{+}, \mathrm{NO}^{+}, \mathrm{N}^{+}$and electrons; neutral, electron and ion temperature; 3-D neutral winds; and ionospheric electric field. The GCITEM-IGGCAS can reproduce the main features of the coupled thermosphere and ionosphere system (see Ren ZP et al., 2009 for details).

Because of the spherical geographical coordinate system used in it, GCITEM-IGGCAS cannot self-consistently calculate the heat flux and plasma flux at the upper boundary, so we have had to obtain these fluxes from an empirical model. The TIME3D-IGGCAS is a three-dimension theoretical ionospheric model (Ren ZP et al., $2012 a, b)$ that cover the whole ionosphere and the whole plasmasphere, and can self-consistently calculate the time-dependent three-dimensional structures of their main parameters in realistic geomagnetic fields, including electron and main ion $\mathrm{CO}^{+}, \mathrm{H}^{+}, \mathrm{He}^{+}$, $\mathrm{NO}^{+}, \mathrm{O}_{2}{ }^{+}, \mathrm{N}_{2}{ }^{+}$) number densities; electron and ion temperatures; and field-aligned ion velocities.

The TIME3D-IGGCAS and GCITEM-IGGCAS models can two-way couple with each other. In this condition, the GCITEM-IGGCAS closes its ionosphere module, and runs the TIME3D-IGGCAS as its ionosphere-plasmasphere module. The TIME3D-IGGCAS will obtain the neutral composition, neutral density, neutral winds, and ionospheric electric fields from the GCITEM-IGGCAS model, and provide to the GCITEM-IGGCAS model the self-consistent calculated ion composition, ion $\left(\mathrm{O}^{+}, \mathrm{H}^{+}, \mathrm{He}^{+}, \mathrm{NO}^{+}, \mathrm{O}_{2}{ }^{+}, \mathrm{N}_{2}{ }^{+}\right)$and electron densities, ion and electron temperatures, and field-aligned ion velocities at the height of the ionosphere.

This coupled GCITEM-TIME3D model is used in this investigation. The following simulations (4 cases) are performed at the December Solstice for low $\left(F_{107}, F_{107 \mathrm{~A}}=70,2\right.$ cases $)$ or high $\left(F_{107}, F_{107 \mathrm{~A}}=\right.$ 210,2 cases) solar activity levels, and geomagnetic quiet input with a cross cap potential of $20 \mathrm{kV}$ and auroral particle precipitation with a hemispheric power of $10 \mathrm{GW}$. An IGRF geomagnetic field is used in these simulations. The GCITEM-TIME3D's initial and low boundary conditions are derived primarily from MSISO0, HWM93, and IRI 2000 empirical models. However, the low boundary, which is at the height of $90 \mathrm{~km}$, uses the zonal mean states of neutral temperature, neutral density, and neutral compositions from the MSISOO empirical model and the neutral temperature and density tides from TIMED/SABER observations. These tides include the migrating diurnal tide and the migrating semi-diurnal tide. The details of calculations of these tides from TIMED/SABER observations can be seen in Ren ZP et al. (2011) and Wan W et al. (2012). The low boundary tidal wind is not derived from the input, but from the self-consistent calculation based on the low boundary neutral temperature and neutral density. To analyze the influence of atmospheric tide on the annual anomalies, we use the June Solstice atmospheric tide in some simulations ( 2 cases) and the December Solstice tide in others (2 cases). Figure 1 shows the 
latitudinal variations in the amplitude of the December neutral temperature diurnal tide (black cycle line), the December semidiurnal tide (black star line), the June diurnal tide (red cycle line), and the June semidiurnal tide (red star line) at the low boundary of the GCITEM-IGGCAS, in units of K. As shown in Figure 1, an obvious annual asymmetry can be observed in atmospheric tides, and the asymmetry of the semidiurnal tide is stronger than that of the diurnal tide. To keep removing all the effects of the initial conditions, 15 model day runs were made in all simulations to obtain the presented results.

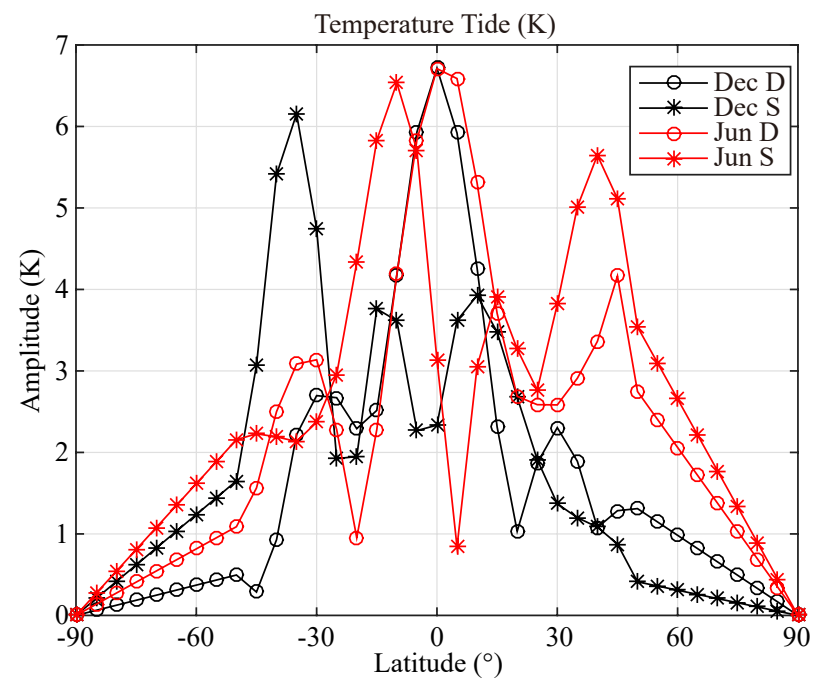

Figure 1. Latitudinal variations of the amplitude of December neutral temperature diurnal tide (black cycle line), December semidiurnal tide (black star line), June diurnal tide (red cycle line), and June semidiurnal tide (red star line) at the low boundary of the GCITEM-IGGCAS, in units of $\mathrm{K}$.

\section{Result and Discussions}

Similar to Ren ZP et al. (2014), we focus primarily on the influence of atmospheric tide on the ionospheric zonal mean states, and will analyze mainly the longitudinal and diurnal mean (zonal mean) ionospheric states. The distributions of ionospheric plasma density depend on the geomagnetic field, and the geomagnetic latitude varies with geographic longitude. Thus, we calculate the ionospheric mean states in the quasi-dipole coordinate system (see Richmond, 1995 and Ren ZP et al., 2008 for details).

Figure 2a shows latitudinal and altitudinal variations of the zonal mean of the ionospheric electron densities at the December Solstice for low solar activity levels (case 1); Figure 2 b shows ionospheric latitudinal and altitudinal variations at the December Solstice driven with the June tide (case 2). We observe that the electron densities in Figures $2 \mathrm{a}$ and $2 \mathrm{~b}$ show similar latitudinal and altitudinal variations, and that their differences are slight. With the 'fountain effect', the equatorial ionization anomaly (EIA) appears in the mean electron densities; the low-latitude ionosphere is higher than the mid- and high-latitude ionosphere in both cases. The obvious ionospheric summer-winter (South-North) asymmetries both appear in Figures $2 a$ and $2 b$, and the electron density in the Southern Hemisphere (summer hemisphere) is signific- antly higher than that in the Northern Hemisphere (winter hemisphere).

To analyze the effects of tide, we calculated the relative differences between these two cases as follows:

$$
\delta N e=\frac{N e_{\text {JuneTide }}-N e_{\text {DecemberTide }}}{N e_{\text {DecemberTide }}} \times 100 \% .
$$

Figure 2c shows the latitudinal and altitudinal variations of $\delta \mathrm{Ne}$ in units of \%; the solid lines in this figure are the zero lines. Because in these two simulations most of the inputs and boundary conditions are the same, $\delta \mathrm{Ne}$ must be driven by the annual asymmetry in the atmospheric tide (that is, by the June-December difference in the atmospheric tide), and must express the influence of atmospheric tide on the annual asymmetry of the zonal mean ionospheric electron density. As shown in Figure 2c, the value of $\delta \mathrm{Ne}$ varies mainly between $-20 \%$ and $10 \%$, and this asymmetry shows obvious latitudinal and altitudinal variations. We first focus on the altitudinal variation of $\delta \mathrm{Ne}$. At lower altitudes (below about $200 \mathrm{~km}), \delta N e$ is mainly larger than zero, and the June tide increases the zonal mean electron density. At higher altitudes (above about $200 \mathrm{~km}$ ), $\delta \mathrm{Ne}$ is mainly less than zero, and the June tide decreases the zonal mean electron density. The obvious summer-winter (South-North) asymmetries can also be found in Figure $2 c$, and it is suggested that the influence of atmospheric tide shows obvious latitude variation. There is a positive region at the equator and in the low latitudes of the summer hemisphere near the height of $300 \mathrm{~km}$.

To analyse the details, Figure 3 shows the altitudinal profiles of latitudinal mean $\delta \mathrm{Ne}$ (black solid line), $\delta \mathrm{Ne}$ at $-45^{\circ}$ (summer middle latitude, black cycle line), $\delta N e$ at $-15^{\circ}$ (summer EIA region, black star line), $\delta \mathrm{Ne}$ at $0^{\circ}$ (red solid line), $\delta \mathrm{Ne}$ at $15^{\circ}$ (winter EIA region, red star line), and $\delta \mathrm{Ne}$ at $45^{\circ}$ (winter middle latitude, red cycle line) in units of \%. Although all profiles show similar altitudinal variations in the lower thermosphere region, the altitudinal variations show large differences at higher altitudes. The latitudinal mean $\delta N e$ profile shows the global mean ionospheric response to atmospheric tide, and its altitudinal variation is more consistent with the profile at middle latitude of the summer hemisphere (Southern Hemisphere). The latitudinal mean $\delta \mathrm{Ne}$ profile below $180 \mathrm{~km}$ shows weak positive value and above $180 \mathrm{~km}$ shows negative value. The negative value increases with altitude between $180 \mathrm{~km}$ and $450 \mathrm{~km}$, reaching its maximum near $450 \mathrm{~km}$, and decreases with altitude above $450 \mathrm{~km}$.

In addition to the altitudinal variations, $\delta N e$ also shows complex latitudinal variations, which vary with altitude. At lower altitude (below $180 \mathrm{~km}$ ), the latitudinal and altitudinal variations are not significant, and $\delta N e$ keeps a weak positive value. The ions at low ionosphere are mainly molecular, and the plasma densities are controlled by photochemistry. Hence, the low ionospheric latitudinal variations are mainly controlled by latitudinal variation of the solar zenith angle, and the latitudinal variations of $\delta \mathrm{Ne}$ are not significant. However, we observe that there is a small-scale structure at middle latitude of the winter hemisphere (Northern Hemisphere) that may be driven by the vertical propagation of the atmospheric tide. Lindzen (1967) suggested that the diurnal tide can break down in the mesosphere-lower thermosphere (MLT) re- 
(a) Electron density in Case $1\left(10^{11} \mathrm{~m}^{-3}\right)$

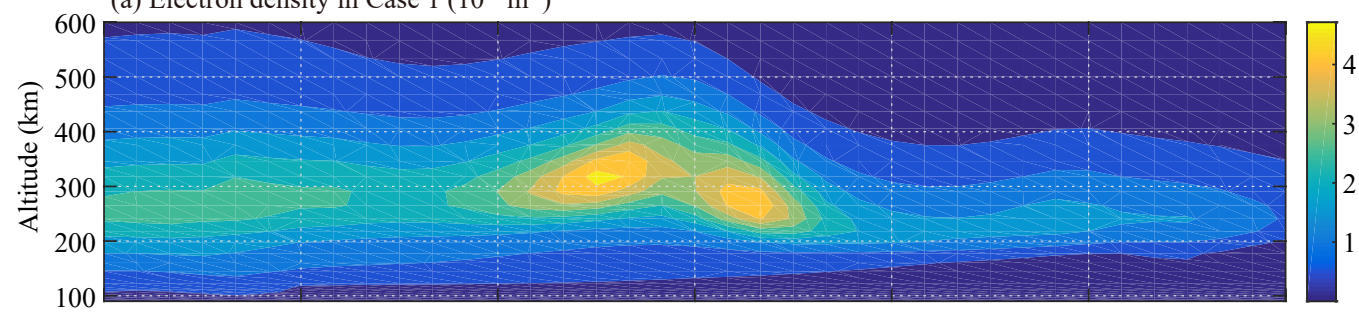

(b) Electron density in Case $2\left(10^{11} \mathrm{~m}^{-3}\right)$

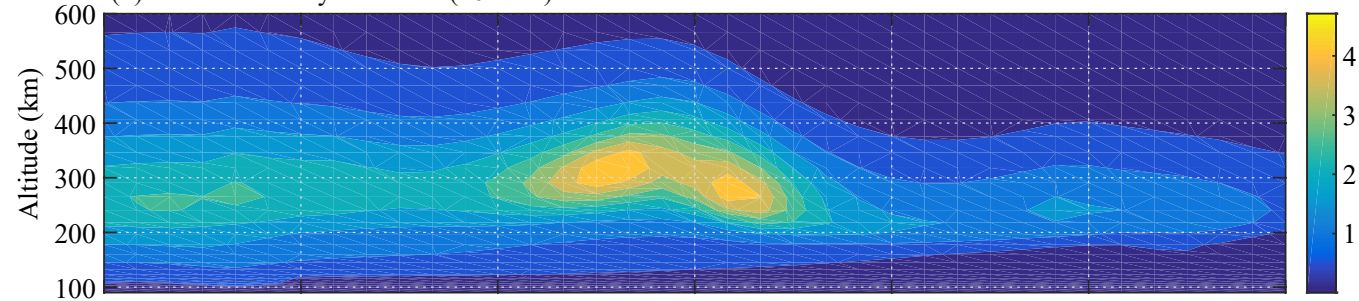

(c) Difference in electron density (\%)

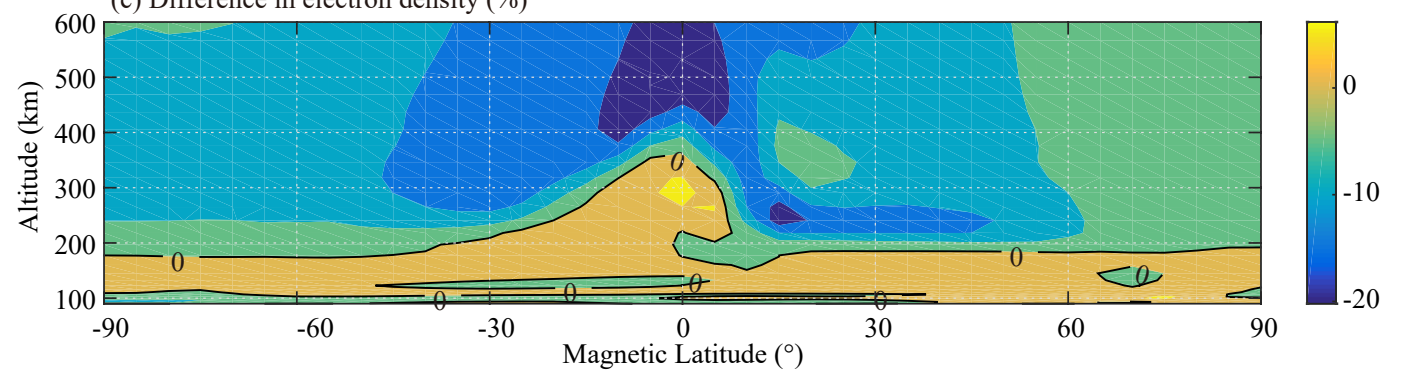

Figure 2. Altitudinal and latitudinal variations of the simulated zonal mean electron densities, in units of $10^{11} \mathrm{~m}^{-3}$, at December, (a) driven by the December atmospheric tide, and (b) driven by the June atmospheric tide. (c) The relative difference ( $\delta \mathrm{Ne}$ ) of the zonal mean electron densities between the two simulations (a) and (b), in units of $\%$.

gion, generate turbulence, enhance the eddy mixing, and change the chemical composition in the MLT region and in the higher thermosphere. Because diurnal and semidurunal tides can affect the eddy mixing and change the chemical compositions in MLT region, atmospheric tide can change the $\mathrm{NO}$ and $\mathrm{O}_{2}$ densities in the E-region, and affect the E-region molecular ion (and electron) densities (see Ren ZP et al., 2012b, 2014).

Because ionospheric dynamics play a more important role in the higher than in the lower ionosphere, the altitudinal and latitudinal variations of $\delta \mathrm{Ne}$ at the higher ionosphere are more complex than at the lower ionosphere. Moreover, the latitudinal variations at the higher ionosphere are greater than at the lower, and $\delta \mathrm{Ne}$ at low-latitudes and at mid- and high-latitudes show different features, which may be driven by different mechanisms. At mid- and high-latitudes, there are obvious latitudinal variations and summer-winter asymmetry (or Southern Hemisphere-Northern Hemisphere asymmetry). At middle latitude of the Southern Hemisphere (summer hemisphere, $-45^{\circ}$ ), the $\delta N e$ profile (black cycle line in Figure 3) above $180 \mathrm{~km}$ shows negative value, which increases with altitude between 180 and $300 \mathrm{~km}$, reaches its maximum near $300 \mathrm{~km}$, and decreases with altitude above $300 \mathrm{~km}$. Above $180 \mathrm{~km}$ at middle latitude of the Northern Hemisphere (winter hemisphere, $45^{\circ}$ ), the $\delta N e$ profile (red cycle line in Figure 3 ) also shows negative value, which increases with altitude between 180 and $240 \mathrm{~km}$, reaches its maximum near $240 \mathrm{~km}$, decreases with altitude between 240 and $330 \mathrm{~km}$, and increases with alti- tude above $330 \mathrm{~km}$. By transporting ions and electrons, the dynamic mechanism can affect the ionospheric electron density, and the wind blowing from the summer hemisphere (Southern Hemisphere) to the winter hemisphere (Northern Hemisphere) may play an important role in the summer-winter asymmetry (or Southern Hemisphere-Northern Hemisphere asymmetry). In addition to dynamic mechanisms, chemical mechanisms may also be important. As mentioned above, atmospheric tide enhances eddy diffusions, can cause enhanced downward transport of atomic oxygen and upward transport of $\mathrm{O}_{2}$ and $\mathrm{N}_{2}$, can change the chemical compositions in high thermosphere, and can affect the F-region ionospheric chemical mechanisms.

Different from $\delta \mathrm{Ne}$ at mid- and high-latitudes, which are mainly negative, $\delta \mathrm{Ne}$ at low-latitudes and the equator appears positive in some regions. At the equator, the $\delta \mathrm{Ne}$ profile (red solid line in Figure 3) is positive from 180 to $360 \mathrm{~km}$ and negative above 360 $\mathrm{km}$. The positive value increases with altitude between 180 and $290 \mathrm{~km}$, reaches its maximum near $290 \mathrm{~km}$, and decreases with altitude between 290 and $360 \mathrm{~km}$. The negative value increases with altitude between 360 and $520 \mathrm{~km}$, reaches its maximum near $520 \mathrm{~km}$, and decreases with altitude between 520 and $600 \mathrm{~km}$. In the low latitudes of the Northern Hemisphere (winter hemisphere, $15^{\circ}$ ), the $\delta N e$ profile (red star line in Figure 3) above $180 \mathrm{~km}$ also shows negative values. The negative value increases with altitude between 180 and $240 \mathrm{~km}$, reaches its maximum near $240 \mathrm{~km}$, decreases with altitude between 240 and $370 \mathrm{~km}$, and increases with 


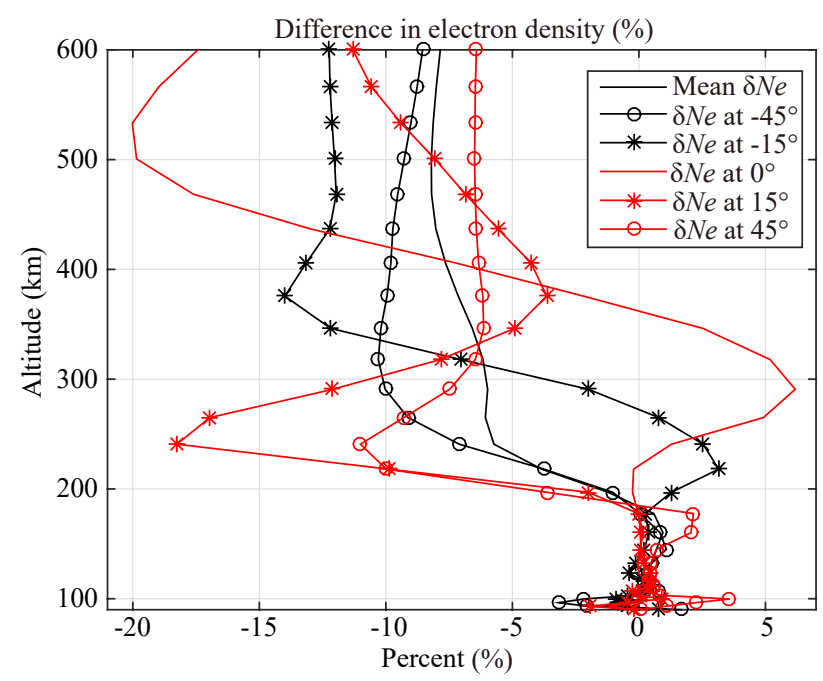

Figure 3. The altitudinal profiles of latitudinal mean $\delta \mathrm{Ne}$ (solid line), $\delta \mathrm{Ne}$ at $-45^{\circ}$ (summer middle latitude, dashed line), $\delta \mathrm{Ne}$ at $-15^{\circ}$ (summer ElA region, star line), $\delta \mathrm{Ne}$ at $0^{\circ}$ (cycle line), $\delta \mathrm{Ne}$ at $15^{\circ}$ (winter EIA region, plus line), and $\delta \mathrm{Ne}$ at $45^{\circ}$ (winter middle latitude, cross line) in units of $\%$.

altitude above $370 \mathrm{~km}$. In the low latitudes of the Southern Hemisphere (summer hemisphere, $-15^{\circ}$ ), the $\delta \mathrm{Ne}$ profile (black star line in Figure 3) is positive from 180 to $280 \mathrm{~km}$ and negative above $280 \mathrm{~km}$. The positive value increases with altitude between 180 and $220 \mathrm{~km}$, reaches its maximum near $220 \mathrm{~km}$, and decreases with altitude between 220 and $280 \mathrm{~km}$. The negative value increases with altitude between 280 and $380 \mathrm{~km}$, reaches its maximum near $380 \mathrm{~km}$, and decreases with altitude between 380 and $600 \mathrm{~km}$. As shown in Figures 2 and 3, $\delta \mathrm{Ne}$ at low-latitudes and the equator mainly appears positive at lower altitude, and appears negative at higher altitude. As shown in Figure $2 c$, the height of the zero line varies with geomagnetic latitude, and the altitudinal peak of the zero line appears at the magnetic equator. Actually, we can say that EIA appears in $\delta N e$, and this structure is driven by the 'fountain effect' and upward equatorial vertical $E \times B$ plasma drifts. Previous research has suggested that atmospheric tide can affect the ionospheric dynamo, and drive vertical drifts and the ionospheric equatorial ionization anomaly structure (EIA) near the magnetic equator (e.g. Jin et al., 2008; Ren ZP et al., 2009, 2010). Through ionospheric dynamo, the annual asymmetry of atmospheric tide can drive annual asymmetry in the vertical drifts near the magnetic equator, and drive annual asymmetry in the ionospheric EIA.

Previous investigations implied that the ionospheric annual anomalies may vary with solar activity level. Hence, we also compare $\delta N e$ at high solar activity level with that at low solar activity level. Figures $4 \mathrm{a}$ and $4 \mathrm{~b}$ respectively show the latitudinal and altitudinal variations of zonal mean ionospheric electron densities for low solar activity level and for high solar activity level; Figure $4 \mathrm{c}$ shows the difference between Figures $4 \mathrm{a}$ and $4 \mathrm{~b}$. The solid lines in Figures $4 a, 4 b$, and $4 c$ are the zero lines. At the lower ionosphere,

(a) Difference for low solar activity (\%)

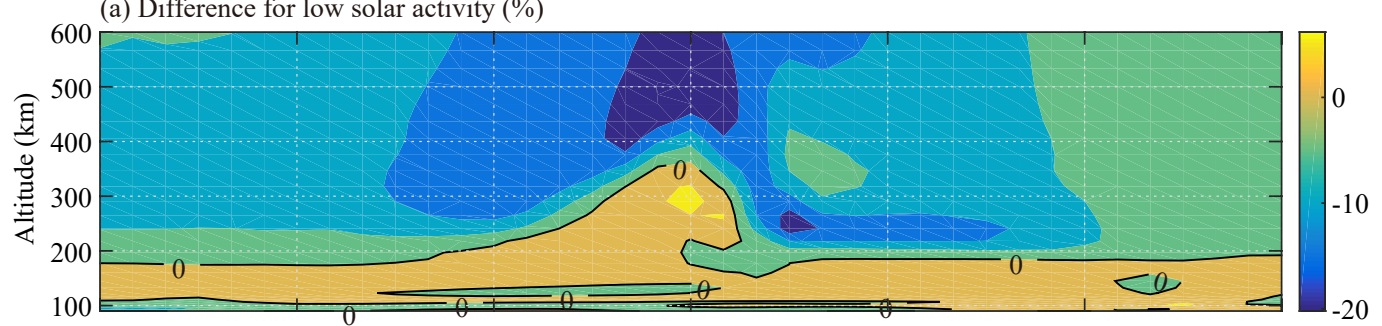

(b) Difference for high solar activity (\%)

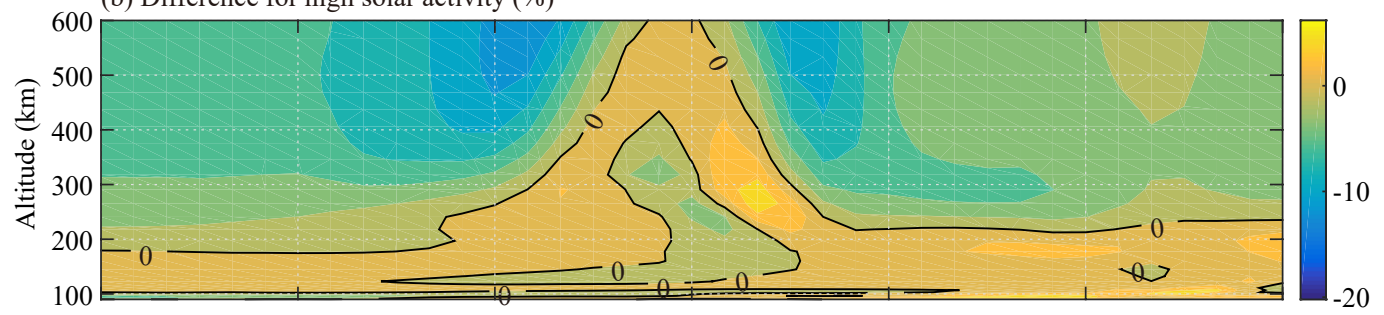

(c) Difference for low and high solar activity (\%)

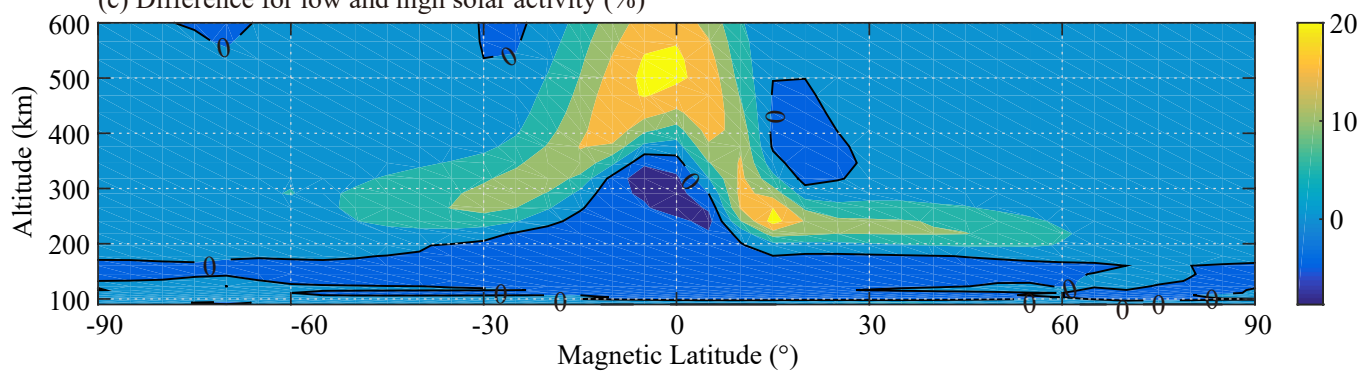

Figure 4. The altitudinal and latitudinal variations of the relative difference of the zonal mean electron densities for (a) low solar activity level, for (b) high solar activity level, and (c) for their difference. 
the difference between $\delta \mathrm{Ne}$ at high solar activity level and at low solar activity level is very slight, and the annual anomaly driven by atmospheric tide does not vary significantly with the increase of solar activity. At higher mid- and high-latitude ionosphere, although $\delta \mathrm{Ne}$ at high solar activity levels are mainly smaller than at low solar activity levels, the annual anomaly driven by atmospheric tide mainly decreases with the increase of solar activity. At lowlatitude ionosphere, the EIA structure also appears in the $\delta \mathrm{Ne}$ at high solar activity level; an EIA-like structure can be found in Figure 4c. Because the equatorial daytime upward drift for high solar flux levels is stronger than for low solar flux levels, the spatial scale of the EIA is larger than that at low solar activity levels.

\section{Summary and Conclusion}

The ionospheric annual anomaly is an important ionospheric seasonal variation. Based on the GCITEM-IGGCAS model, we simulated the influence of the annual asymmetry of atmospheric tide on the ionospheric annual anomalies. Through respectively adding June tide and December tide at the model's low boundary, we find that the tidal influence on the annual anomalies of the ionospheric electron density varies with latitude, altitude, and solar activity level. Compared with the December tide, the June tide mainly increases the ionospheric electron density below the height of $200 \mathrm{~km}$, and mainly decreases the electron density above the height of $200 \mathrm{~km}$. In the low-latitude ionosphere, tide affects the equatorial ionization anomaly structure (EIA) above the height of $200 \mathrm{~km}$, which suggests that tide affects the equatorial vertical $E \times B$ plasma drifts. Although below the height of $200 \mathrm{~km}$ the tide-driven ionospheric annual anomalies vary insignificantly with the solar flux level, above the height of $200 \mathrm{~km}$ the annual anomalies mainly decrease with solar activity.

\section{Acknowledgments}

This work is supported by the Strategic Priority Research Program of Chinese Academy of Sciences (Grant No. XDA17010201), the National Natural Science Foundation of China (41674158, $41874179,41621063,41427901,41474133,41322030)$, the Youth Innovation Promotion Association CAS (2014057), and the Opening Funding of Chinese Academy of Sciences dedicated for the Chinese Meridian Project.

\section{References}

Dang, T., Wang, W. B., Burns, A., Dou, X. K., Wan, W. X., and Lei, J. H. (2017). Simulations of the ionospheric annual asymmetry: Sun-Earth distance effect. J. Geophys. Res. Space Phys., 122(6), 6727-6736.

https://doi.org/10.1002/2017JA024188

Forbes, J. M., Roble, R. G., and Fesen, C. G. (1993). Acceleration, heating, and compositional mixing of the thermosphere due to upward propagating tides. J. Geophys. Res. Space Phys., 98(A1), 311-321. https://doi.org/10.1029/92JA00442

Forbes, J. M., Zhang, X., Palo, S., Russell, J., Mertens, C. J., and Mlynczak, M. (2008). Tidal variability in the ionospheric dynamo region. J. Geophys. Res. Space Phys., 113(A2), A02310. https://doi.org/10.1029/2007JA012737

Jin, H., Miyoshi, Y., Fujiwara, H., and Shinagawa, H. (2008). Electrodynamics of the formation of ionospheric wave number4 longitudinal structure. J. Geophys. Res. Space Phys., 113, A09307. https://doi.org/10.1029/2008JA013301

Jones, M. Jr., Forbes, J. M., Hagan, M. E., and Maute, A. (2014). Impacts of vertically propagating tides on the mean state of the ionosphere-thermosphere system. J. Geophys. Res. Space Phys., 119(3), 2197-2213. https://doi.org/10.1002/2013JA019744

Lei, J. H., Wang, W. B., Burns, A. G., Luan, X. L., and Dou, X. K. (2016). Can atomic oxygen production explain the ionospheric annual asymmetry?. J. Geophys. Res. Space Phys., 121(7), 7238-7244. https://doi.org/10.1002/2016JA022648

Lindzen, R. S. (1967). Thermally driven diurnal tide in the atmosphere. Quart. J. Roy. Meteor. Soc., 93(395), 18-42. https://doi.org/10.1002/qj.49709339503

Liu, L. B., Zhao, B. Q., Wan, W. X., Venkartraman, S., Zhang, M. L., and Yue, X. (2007). Yearly variations of global plasma densities in the topside ionosphere at middle and low latitudes. J. Geophys. Res. Space Phys., 112(A7), A07303. https://doi.org/10.1029/2007JA012283

Mendillo, M., Huang, C. L., Pi, X. Q., Rishbeth, H., and Meier, R. (2005). The global ionospheric asymmetry in total electron content. J. Atmos. Sol. Terr. Phys., 67(15), 1377-1387. https://doi.org/10.1016/j.jastp.2005.06.021

Mikhailov, A. V., and Perrone, L. (2011). On the mechanism of seasonal and solar cycle $N_{m} F_{2}$ variations: A quantitative estimate of the main parameters contribution using incoherent scatter radar observations. J. Geophys. Res. Space Phys., 116(A3), A03319. https://doi.org/10.1029/2010JA016122

Mikhailov, A. V., and Perrone, L. (2015). The annual asymmetry in the $F_{2}$ layer during deep solar minimum (2008-2009): December anomaly. J. Geophys. Res. Space Phys, 120(2), 1341-1354. https://doi.org/10.1002/2014JA020929

Mukhtarov, P., Pancheva, D., and Andonov, B. (2009). Global structure and seasonal and interannual variability of the migrating diurnal tide seen in the SABER/TIMED temperatures between 20 and $120 \mathrm{~km}$. J. Geophys. Res. Space Phys., 114(A2), A02309. https://doi.org/10.1029/2008JA013759

Ren, Z. P., Wan, W. X., Wei, Y., Liu, L. B., and Yu, T. (2008). A theoretical model for mid- and low-latitude ionospheric electric fields in realistic geomagnetic fields. Chin. Sci. Bull., 53(24), 3883-3890. https://doi.org/10.1007/s11434008-0404-4

Ren, Z. P., Wan, W. X., and Liu, L. B. (2009). GCITEM-IGGCAS: A new global coupled ionosphere--thermosphere-electrodynamics model. J. Atmos. Sol. Terr. Phys., 71(17-18), 2064-2076. https://doi.org/10.1016/j.jastp.2009.09.015

Ren, Z. P., Wan, W. X., Xiong, J. G., and Liu, L. B. (2010). Simulated wave number 4 structure in equatorial F-region vertical plasma drifts. J. Geophys. Res. Space Phys., 115(A5), A05301. https://doi.org/10.1029/2009JA014746

Ren, Z. P., Wan, W. X., Liu, L. B., and Xiong, J. G. (2011). Simulated longitudinal variations in the lower thermospheric nitric oxide induced by nonmigrating tides. J. Geophys. Res. Space Phys., 116(A4), A04301. https://doi.org/10.1029/2010JA016131

Ren, Z. P., Wan, W. X., Liu, L. B., and Le, H. J. (2012a). TIME3D-IGGCAS: A new three-dimension mid- and low-latitude theoretical ionospheric model in realistic geomagnetic fields. J. Atmos. Sol. Terr. Phys., 80, 258-266. https://doi.org/10.1016/j.jastp.2012.02.001

Ren, Z. P., Wan, W. X., Liu, L. B., Le, H. J., and He, M. S. (2012b). Simulated midlatitude summer nighttime anomaly in realistic geomagnetic fields. J. Geophys. Res. Space Phys., $117(\mathrm{A3}), \mathrm{A} 03323$. https://doi.org/10.1029/2011JA017010

Ren, Z. P., Wan, W. X., Xiong, J. G., and Liu, L. B. (2014). Influence of DE3 tide on the equinoctial asymmetry of the zonal mean ionospheric electron density. Earth Planets Space, 66(1), 117. https://doi.org/10.1186/1880-5981-66-117

Richmond, A. D. (1995). lonospheric electrodynamics using magnetic apex coordinates. J. Geomagn. Geoelectr., 47(2), 191-212. https://doi.org/10.5636/jgg.47.191

Rishbeth, H., and Müller-Wodarg, I. C. F. (2006). Why is there more ionosphere in January than in July? The annual asymmetry in the F2-layer. Ann. Geophys., 24(12), 3293-3311. https://doi.org/10.5194/angeo-24-3293-2006

Rishbeth, H. (2007). Thermospheric targets. Eos, 88(17), 189-193. https://doi.org/10.1029/2007EO170002

Roble, R. G., Ridley, E. C., and Dickinson, R. E. (1987). On the global mean structure of the thermosphere. J. Geophys. Res. Space Phys., 92(A8), 8745-8758. https://doi.org/10.1029/JA092iA08p08745

Roble, R. G. (1995). Energetics of the mesosphere and thermosphere. In R. M. Johnson, et al. (Eds.), The Upper Mesosphere and Lower Thermosphere: $A$ Review of Experiment and Theory (pp. 1-21). Washington: AGU. 
https://doi.org/10.1029/GM087p0001

Sai Gowtam, V., and Tulasi Ram, T. (2017). lonospheric annual anomaly-New insights to the physical mechanisms. J. Geophys. Res. Space Phys., 122(8), 8816-8830. https://doi.org/10.1002/2017JA024170

Su, Y. Z., Bailey, G. J., and Oyama, K. I. (1998). Annual and seasonal variations in the low-latitude topside ionosphere. Ann. Geophys., 16(8), 974-985. https://doi.org/10.1007/s00585-998-0974-0

Wan, W., Ren, Z., Ding, F., Xiong, J., Liu, L., Ning, B., Zhao, B., Li, G., and Zhang, M. L. (2012). A simulation study for the couplings between DE3 tide and longitudinal WN4 structure in the thermosphere and ionosphere. J. Atmos.
Sol. Terr. Phys., 90-91, 52-60. https://doi.org/10.1016/j.jastp.2012.04.011

Zeng, Z., Burns, A., Wang, W. B., Lei, J. H., Solomon, S., Syndergaard, S., Qian, L. Y., and Kuo, Y. H. (2008). lonospheric annual asymmetry observed by the COSMIC radio occultation measurements and simulated by the TIEGCM. J. Geophys. Res. Space Phys., 113(A7), A07305. https://doi.org/10.1029/2007JA012897

Zhao, B., Wan, W., Liu, L., Mao, T., Ren, Z., Wang, M., and Christensen, A. B. (2007). Features of annual and semiannual variations derived from the global ionospheric maps of total electron content. Ann. Geophys., 25(12), 2513-2527. https://doi.org/10.5194/angeo-25-2513-2007 